University of Nebraska - Lincoln

DigitalCommons@University of Nebraska - Lincoln

2006

\title{
Discovery of a New Species of Smicronyx Schoenherr (Coleoptera: Curculionidae)
}

Donald M. Anderson

Systematic Entomology Laboratory, ARS, USDA National Museum of Natural History Washington, D.C. 20013-7012, U.S.A.

Boris A. Korotyaev

Laboratory of Insect Systematics Zoological Institute Russian Academy of Sciences Universitetskaya Nab. 1199034 St. Petersburg, RUSSIA

Steven W. Lingafelter

Systematic Entomology Laboratory, ARS, USDA National Museum of Natural History Washington, D.C. 20013-7012, U.S.A.

Follow this and additional works at: https://digitalcommons.unl.edu/systentomologyusda

Part of the Entomology Commons

Anderson, Donald M.; Korotyaev, Boris A.; and Lingafelter, Steven W., "Discovery of a New Species of Smicronyx Schoenherr (Coleoptera: Curculionidae)" (2006). USDA Systematic Entomology Laboratory. 26. https://digitalcommons.unl.edu/systentomologyusda/26

This Article is brought to you for free and open access by the Entomology Collections, Miscellaneous at DigitalCommons@University of Nebraska - Lincoln. It has been accepted for inclusion in USDA Systematic Entomology Laboratory by an authorized administrator of DigitalCommons@University of Nebraska - Lincoln. 


\title{
Discovery of a New Species of Smicronyx Schoenherr (Coleoptera: Curculionidae)
}

\author{
Donald M. Anderson ${ }^{1}$ \\ Systematic Entomology Laboratory, ARS, USDA \\ National Museum of Natural History \\ Washington, D.C. 20013-7012, U.S.A. \\ Boris A. Korotyaev \\ Laboratory of Insect Systematics \\ Zoological Institute \\ Russian Academy of Sciences \\ Universitetskaya Nab. 1 \\ 199034 St. Petersburg, RUSSIA \\ AND \\ Steven W. Lingafelter \\ Systematic Entomology Laboratory, ARS, USDA \\ National Museum of Natural History \\ Washington, D.C. 20013-7012, U.S.A.
}

\begin{abstract}
Smicronyx obrieni Anderson, Korotyaev, and Lingafelter, a new species associated with ragweed [Ambrosia grayi (A. Nelson) Shinners], was discovered in Krasnodar (Russia) and Texas (United States), and is described.
\end{abstract}

The second author received eight specimens of weevils (Fig. 1) from O.V. Kovalev (Zoological Institute, St. Petersburg, Russia) that were collected in a rice field in Krasnodar Territory of the North Caucasus (Slavyansk District) in 1975. The weevils were identified as Smicronyx, however the species was unlike any known from the Palearctic Region. Since the territory where these weevils were collected is extensively agricultural with several experimental plots, the second author thought that this species could have been introduced from the United States where Smicronyx is represented by at least 70 species (Anderson 1962; O'Brien \& Anderson 1996).

Since acquiring these specimens, we have seen no additional material collected in Krasnodar Territory or other areas of the Caucasus. In 1998, these beetles were sent to the senior author for identification. The material was determined as an undescribed species of Smicronyx from Texas developing on Ambrosia. In 1999, an expedition to Krasnodar Territory was made, however Ambrosia was nearly absent from the area where the series was collected, and no Smicronyx were collected since. This suggests that this species probably did not establish in Russia. We describe the adult of this new species of Smicronyx.

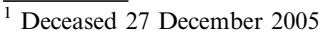




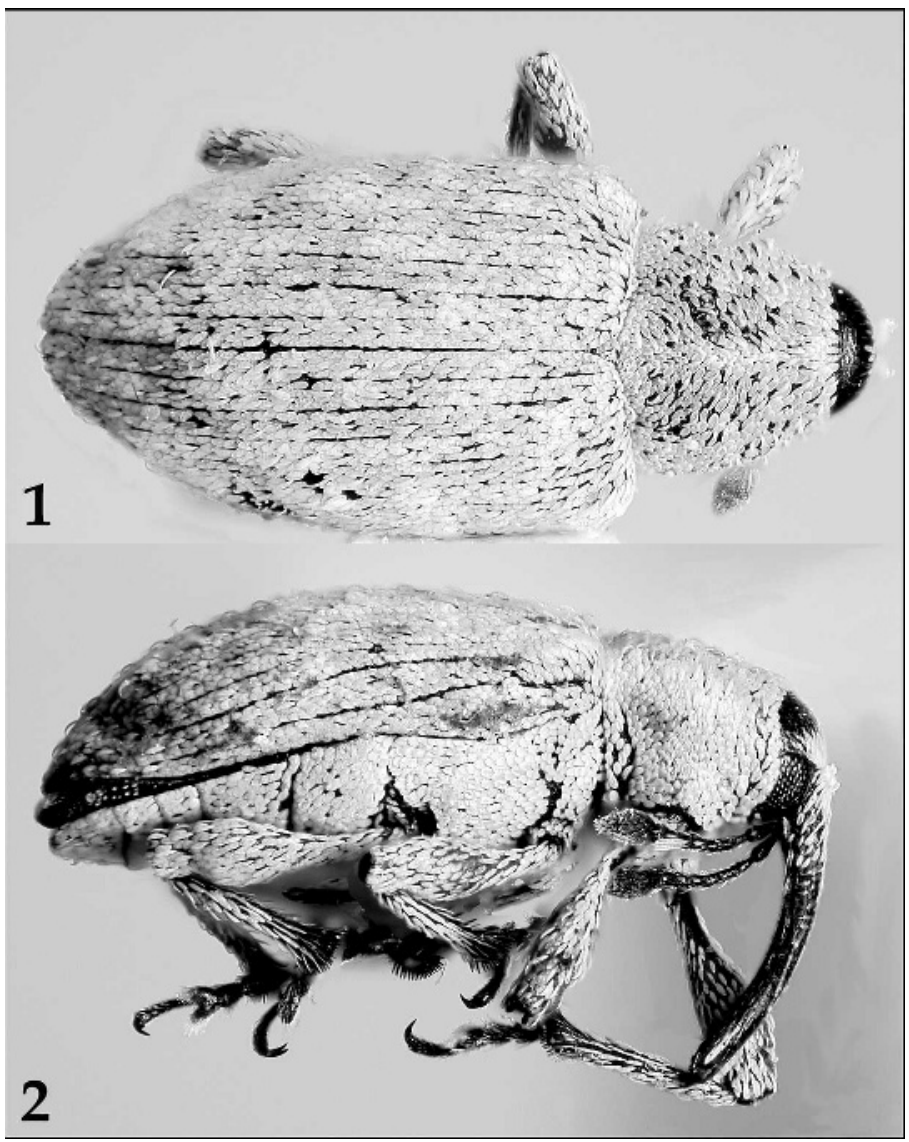

Figs. 1-2. Smicronyx (Pseudosmicronyx) obrieni Anderson, Korotyaev, and Lingafelter, new species, dorsal and lateral views, respectively.

\section{Materials and Methods}

Specimens examined in this study are deposited in the National Museum of Natural History, Washington, D.C., U.S.A. (USNM), the Zoological Institute, Russian Academy of Sciences, St. Petersburg, Russia (ZMAS), the C. W. O'Brien collection, Green Valley, Arizona (CWOC), California Academy of Sciences, San Francisco, California (CASC), Canadian Museum of Nature, Ottawa, Ontario, Canada (CMNC), Texas A\&M University, College Station, Texas (TAMU), Texas Tech University Collection, Lubbock, Texas (TTUC), and The Natural History Museum, London, England (BMNH). Measurements of the specimens were made using a stereoscopic microscope equipped with an ocular micrometer. Terminology follows Korotyaev et al. (2000) and Reidel and O'Brien (1995). 


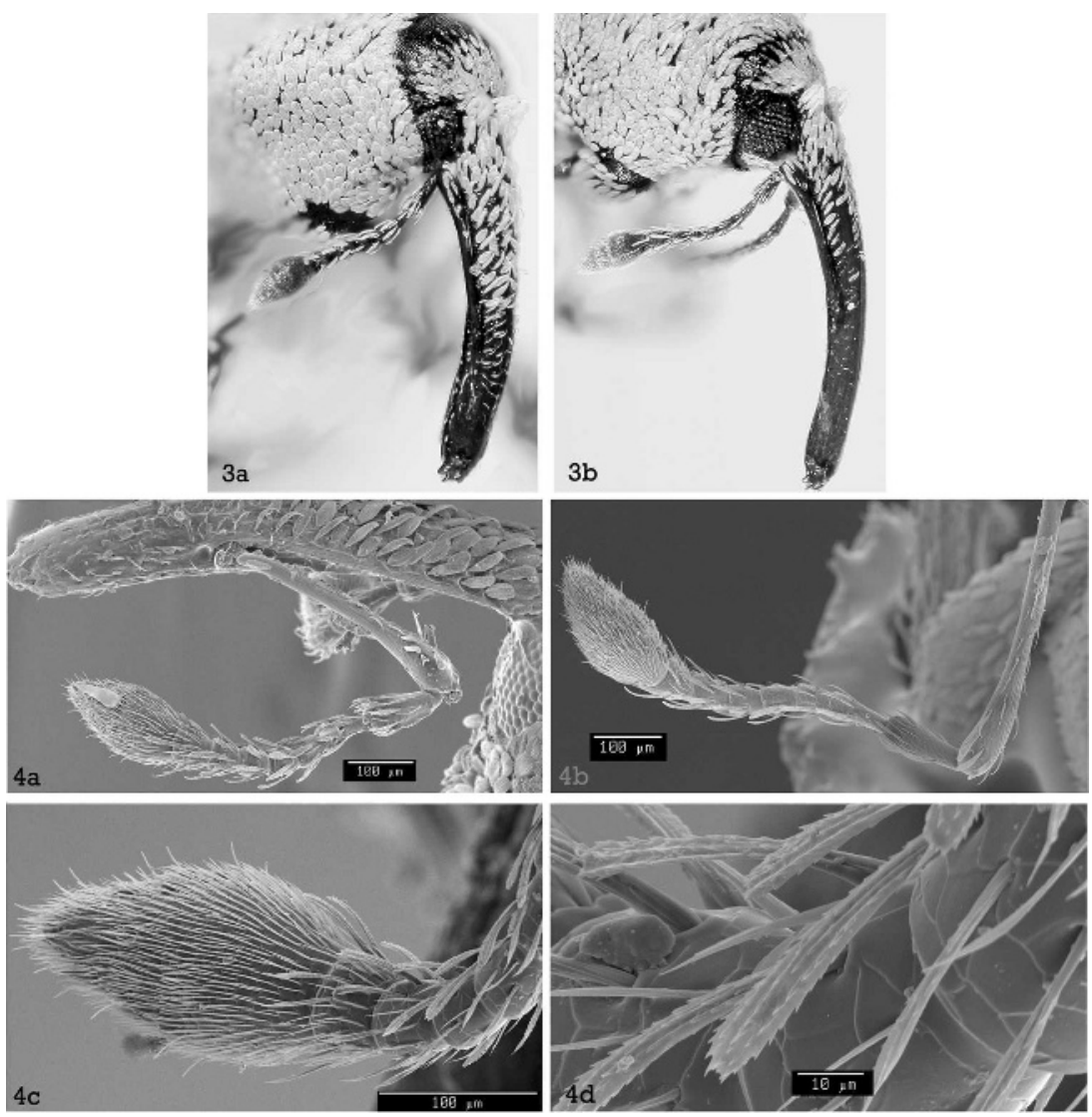

Figs. 3-4. 3) Rostrum and antenna of $S$. obrieni, automontage photograph, dorsolateral view. a, male; b, female. 4) Antenna of $S$. obrieni, scanning electron micrographs. a, male; $b$, female; c, club of female; d, modified setiform scales of antenna.

Smicronyx (Pseudosmicronyx) obrieni Anderson, Korotyaev, and Lingafelter, New Species

Figs. 1-11

Description. Body elliptical, moderately stout, dermal color black. Vestiture abundant, squamulose, pale greyish white, with pearly lustre, shadowy dorsal pattern of pale brown in some specimens (Figs. 1-2). Rostrum (Figs. 3, 5) moderately stout, moderately curved, slightly tapered from base to apex, coarsely punctate behind antennal insertions, with 2 pairs of thin dorsal carinae (obsolete in females) before antennal insertions; scales recumbent except for 2 basal tufts. Basal groove separating rostrum from head shallow, distinct. Mandibles (Fig. 6) distinctly exarate. Head convex, black, shining, reticulate, bearing broad patch of appressed scales behind rostrum. Antennae (Figs. 3-4) inserted near mid-length of rostrum (females, Fig. 3b), or before middle (males, Fig. 3a); first funicular segment stout, subequal to combined length of second and third segments, second distinctly longer than third, remaining 4 segments subequal; setiform scales 

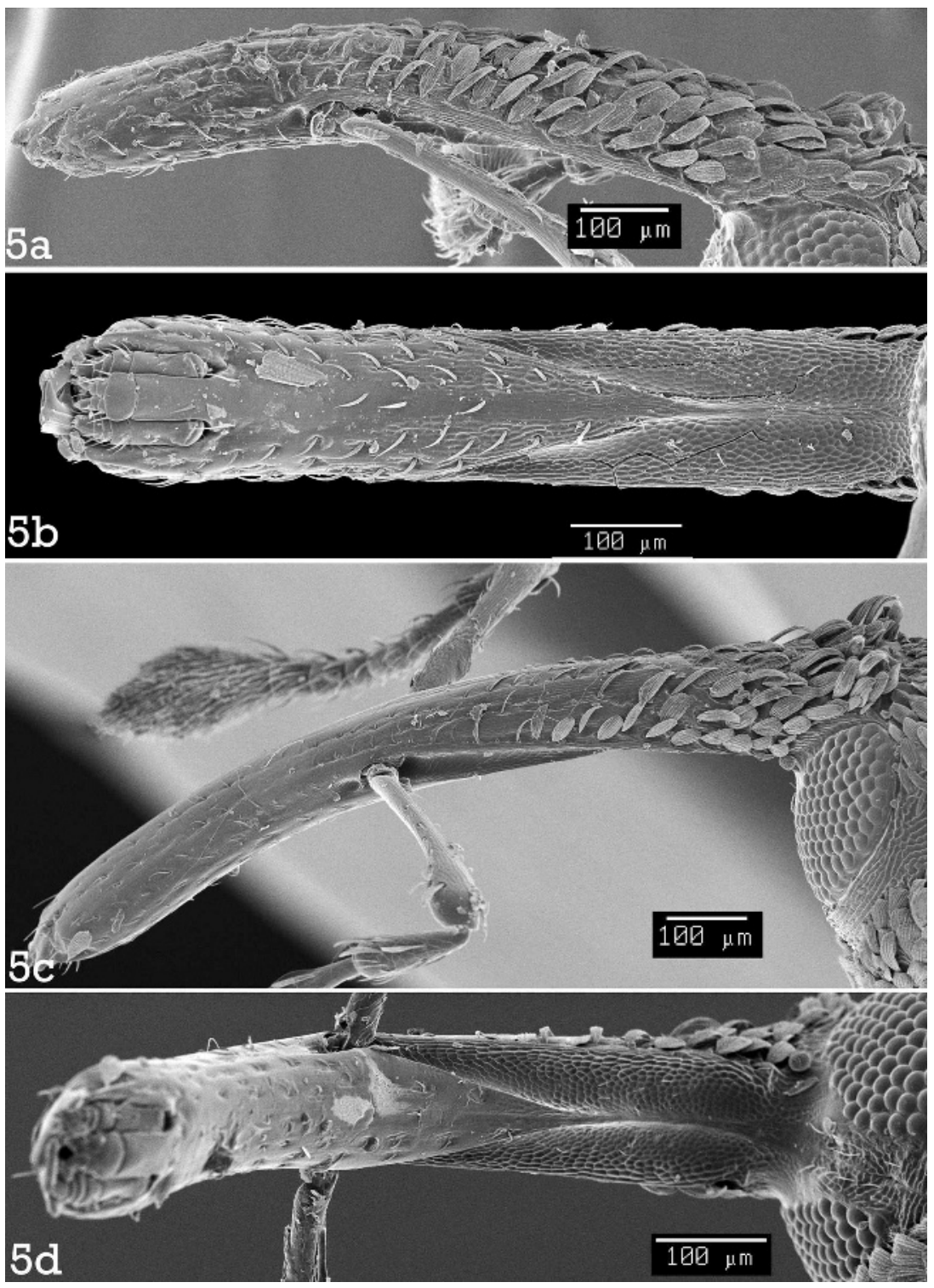

Fig. 5. Rostrum of S. obrieni, scanning electron micrographs. a, male, lateral view; b, male, ventral view; c, female, lateral view; d, female, ventral view.

(Fig. 4d) pale grey, longest on seventh segment; club spindle-shaped, shorter than combined length of segments 3-7 (Fig. 4c). Prothorax moderately convex, slightly broader than long, slightly constricted behind apex; pronotum closely, evenly punctate, shining, without sculpturing, covered with flat, oval scales mixed with arched, flattened, setiform scales (Fig. 1). Elytra moderately convex, sides 

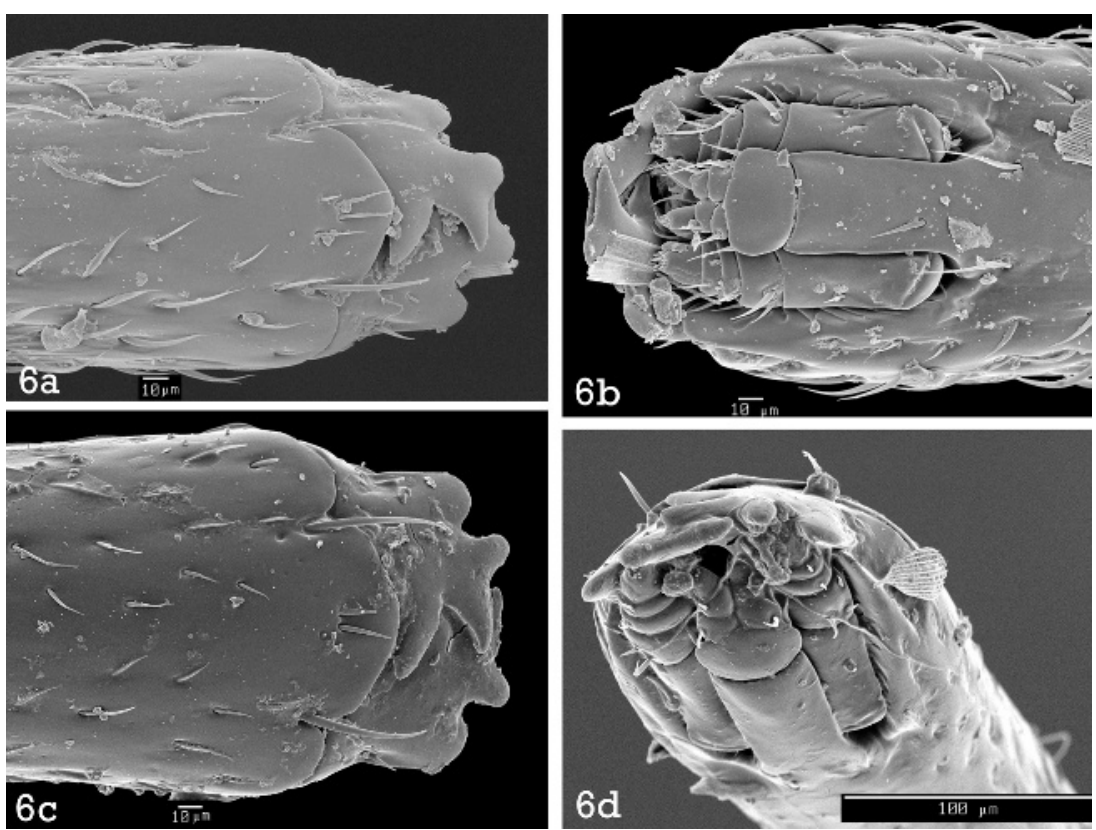

Fig. 6. Mouthparts of S. obrieni, scanning electron micrographs. a, male, dorsal view; b, male, ventral view; c, female, dorsal view; d, female, apico-ventral view.

subparallel for about two-thirds length, converging to obtusely rounded apex, length slightly less than twice width across humeri; intervals flat, finely punctate, covered with 3-4 rows of flat, elliptical, overlapping scales and single row of arched, flattened, setiform scales (Fig. 1). Declivital callosities distinct, not prominent. Scutellum small, subtriangular, squamose. Underside closely covered with ovate, greyish-white scales, with modified striate and/or plumose scales on prosternum (Fig. 9c) and mesosternum (Fig. 9d). First and second ventrites together slightly longer than ventrites $3-5$. Femora moderately clavate, unarmed, reddish brown, clothed with elliptical and elongate appressed scales. Tibiae (Figs. 7b, 8b) straight, reddish brown, thinly covered with mixture of elliptical and elongate appressed scales; row of 4-5 dark, stiff setae on inner margin, reduced to 3 on metatibiae; spurs slightly curved. Tarsi dark, reddish brown, squamose; third tarsomere distinctly broadest, bilobed; fifth tarsomere elongate, slightly longer than second and third tarsomeres combined (Fig. 7c, 8c); claws long, moderately divergent, fused near bases (Figs. 7d, 8d). Male genitalia as illustrated in Fig. 10, internal sac microspiculose, orificial plates fused dorsally; in lateral view, tegmenal strut sinuate with apex weakly, dorsally oriented (Fig. 10c); tegminal arms convergent, but indistinct dorsally. Female genitalia as illustrated in Fig. 11, arms of spiculum ventrale (apodeme of sternite 8) approximately Vshaped and anterior end of stem weakly expanded (Fig. 11a); hemisternites (coxites) weakly convergent apically with weakly divergent styli (Fig. 11a); spermatheca $\mathrm{C}$-shaped but distinctly bulbous at proximal end near spermathecal duct and constricted at opposite end (Fig. 11b), with distinct striations around proximal third and slight indentation at inner margin of spermathecal body. 

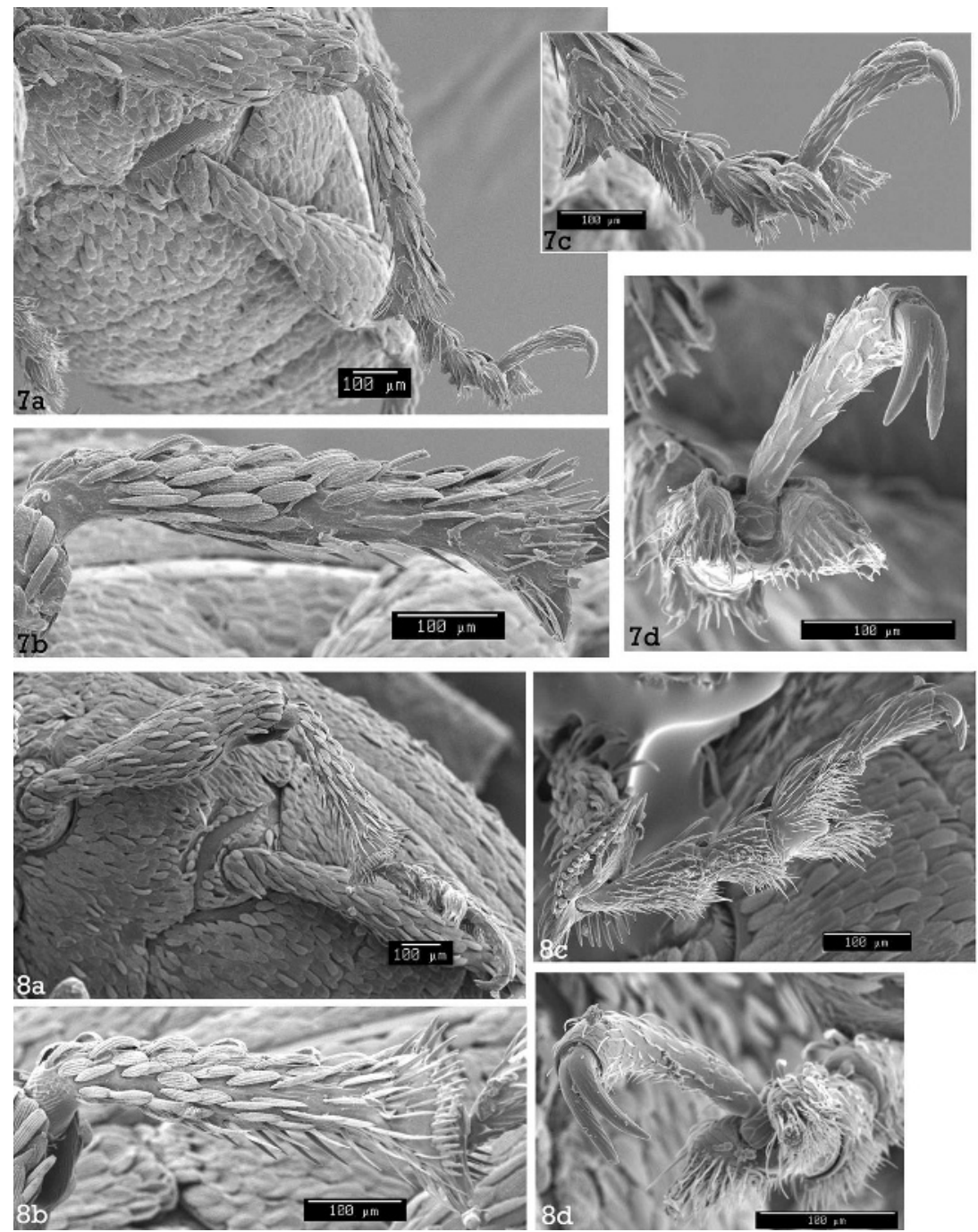

Figs. 7-8. 7) Middle leg of $S$. obrieni, male. a, entire, lateral view; b, mesotibia; c, mesotarsus; d, mesotarsal claws. 8) Middle leg of $S$. obrieni, female. a, entire, lateral view; b, mesotibia; c, mesotarsus; d, mesotarsal claws.

Sexual dimorphism: Males distinguished from females externally by rostrum (Fig. 3) which is longer, smoother, and more polished before antennal insertions in females, and by fifth ventrite of the abdomen which is slightly depressed medially and barely sinuate at anterior margin in males (Fig. 9a), but nearly flat and transverse in females (Fig. 9b).

Measurements (in mm): Taken from specimens collected at one locality $12 \mathrm{mi}$. NE of Floydada, Texas; $\mathrm{n}=25$ males, 25 females. Mean values are in parentheses. Males: Body L. 2.12-2.72 (2.41); Elytra L. 1.48-1.92 (1.69); Elytra 

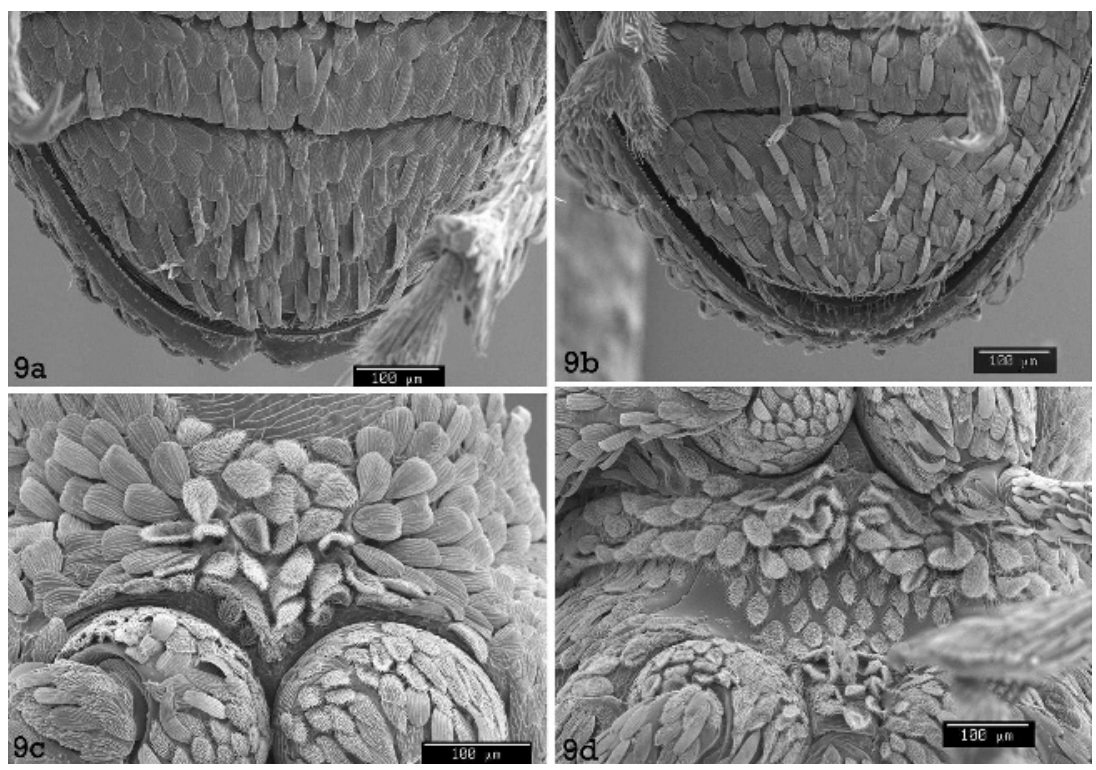

Fig. 9. Venter of S. obrieni: a, apical ventrite of male; b, apical ventrite of female; c, prosternum of female showing modified scales; $d$, mesosternum of female.

W. 0.92-1.28 (1.07); Prothorax L. 0.56-0.76 (0.70); Prothorax W. 0.64-0.88 (0.76); Rostrum L. 0.88-1.12 (0.98). Females: Body L. 1.92-2.84 (2.46); Elytra L. 1.36-2.00 (1.75); Elytra W. 0.84-1.24 (1.09); Prothorax L. 0.48-0.72 (0.65); Prothorax W. 0.60-0.84 (0.75); Rostrum L. 0.88-1.24 (1.08).

Distribution. U.S.A.: Texas, New Mexico, possibly other southwestern states. RUSSIA (?): possibly established in Krasnodar Territory.

Biology. Given the many specimens collected from Ambrosia grayi (A. Nelson) Shinners (Asteraceae) in Texas, this plant is a probable host. This species is active in the late summer on ragweed.

Material Examined. Holotype (male) U.S.A., 12 mi. N[orth] E[ast] Floydada, Floyd Co., Texas, VIII-29-1970, on Ambrosia grayi [at] playa lake, C. R. Ward \& C. W. O'Brien (USNM). Paratypes, U.S.A.: Texas, 12 mi NE Floydada, Floyd Co., playa lake, VIII-29-1970, on Ambrosia grayi, 227 Ex.; same except no host data, col. at night, 8 Ex. (USNM, CWOC). New Mexico, Ute Lake, 8-19-1970, D. Foster, 2 Ex., (CWOC). RUSSIA: Krasnodar Territory, Slavyansk District, "Kuban" collective farm, on rice, VIII-1-1975, 6 Ex. (ZMAS); 2 Ex. (USNM).

Etymology. This species has been named in honor of Dr. Charles W. O'Brien, of Green Valley, Arizona, who took part in collecting the type series, and who kindly loaned those specimens.

Discussion. Some noteworthy features of this species are the long fifth tarsomere (Figs. 7d, 8d), which extends farther beyond the third tarsomere than in most other species of the subgenus Pseudosmicronyx, the slight, but distinct, pearly lustre of the vestiture (Fig. 1), the distinctive sinuate tegminal shape (from lateral view) (Fig. 10c), and the distinctive shape of the spermatheca (Fig. 11b). Smicronyx obrieni clearly belongs to the subgenus Pseudosmicronyx, and shares a number of basic features with the $S$. corniculatus group of species (see 

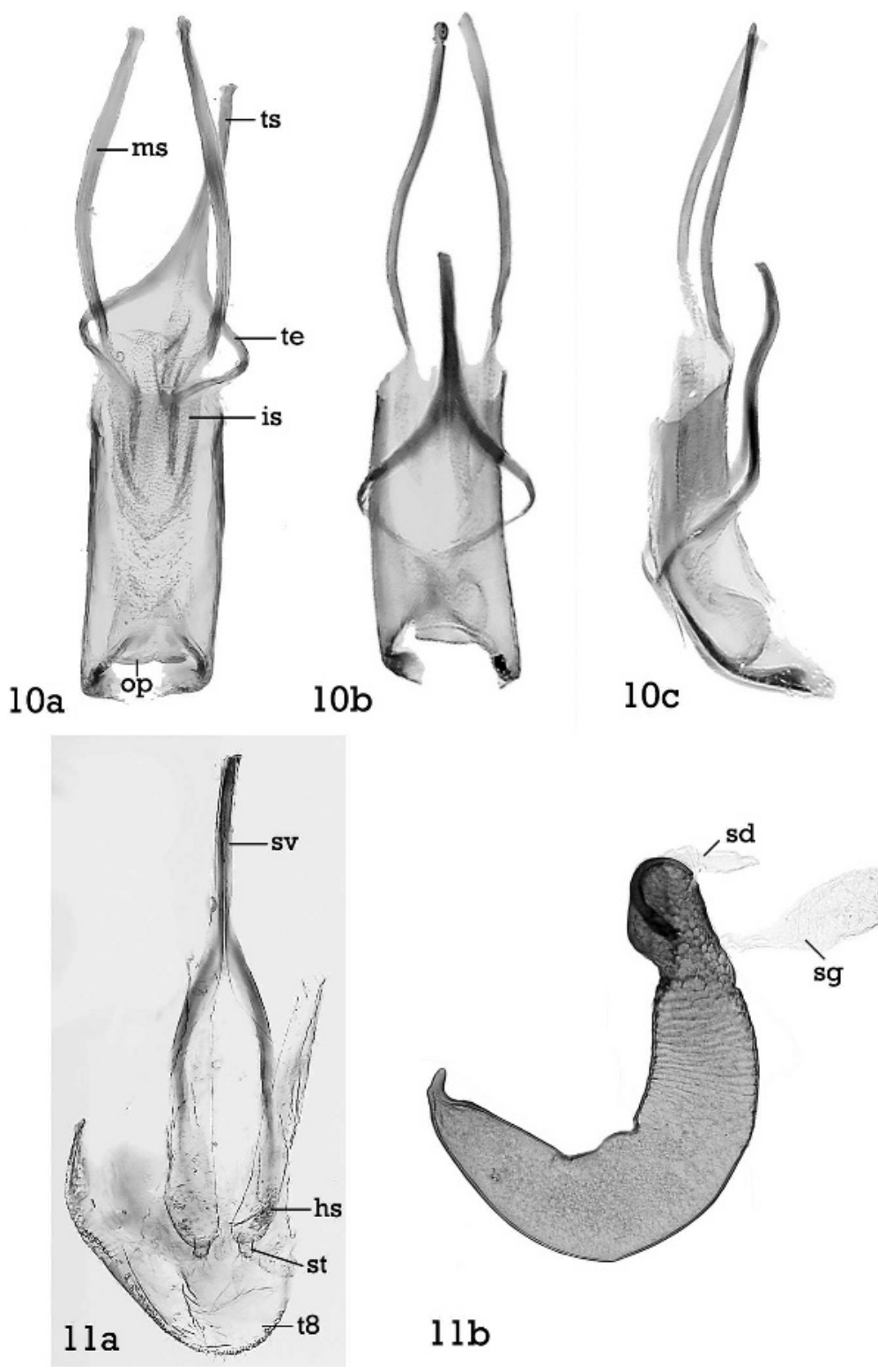

Figs. 10-11. 10) Aedeagus of S. obrieni. a, dorsal view (is $=$ internal sac, $\mathrm{ms}=$ median strut, op $=$ orificial plate, te $=$ tegmen, ts $=$ tegminal strut $)$; , ventral view; $c$, lateral view. 11) Female genitalia. a, vaginal region ( $\mathrm{hs}=$ hemisternite [coxite], $\mathrm{st}=$ stylus, $\mathrm{sv}=$ spiculum ventrale [apodeme of sternite 8], t8 = tergite 8$)$; b, spermatheca $(\mathrm{sd}=$ spermathecal duct, $\mathrm{sg}=$ spermathecal gland). 
Anderson, 1962), of which several species are also associated with species of Ambrosia or the related genus Iva. However, the rostrum of female S. obrieni (Figs. 3b, 5c, d) is not as polished and terete before the antennal insertions as in the corniculatus group. Also, the surface of the pronotum is not sculptured with wavy ridges between the punctures, as in many species of the corniculatus group. Thus, the relationship of $S$. obrieni to the latter group remains unclear.

Two other undescribed species of Smicronyx resembling $S$. obrieni from Texas (CWOC) have a similar body shape and pale vestiture. Those species differ from $S$. obrieni in having shorter fifth tarsomeres, different punctation of the pronotum, and different shape and sculpturing of the rostrum. It should also be noted that $S$. obrieni may also be confused with other described species in the western USA having a similar habitus, particularly Smicronyx pallidus Anderson and $S$. albidosquamosus Klima, however the aforementioned characters will distinguish them. The latter two species have not yet been recorded from Texas or New Mexico. The status of the undescribed species mentioned here is based upon Anderson's revision of the Smicronyx species of America north of Mexico (1962), and on his examination of the type specimens of the described Mexican Smicronyx species. The collection of the series of S. obrieni in Russia "on rice" is presumed incidental and we do not believe this is a host plant since the host of the long series from Texas was apparently $A$. grayi.

\section{Acknowledgments}

We thank O. V. Kovalev, C. W. O'Brien, E. G. Riley (TAMU), R. Davidson (Carnegie Museum), and P. Perkins (MCZ) for providing important material to this study. Thanks to the Ernst Mayr Committee for providing a grant to BAK to travel to the MCZ. Lisa Roberts (SEL, USDA) prepared the scanning electron micrographs and automontage genitalic photos. Charyn Micheli (SEL, USDA, University of Maryland) prepared the automontage photographs of the dorsal and lateral weevil views. BAK was supported by funds from USDA and by grants of the Russian Foundation for Basic Research No. 04-04-49109 and 04-04-81026Bel2004a. Allen Norrbom (SEL, USDA), Charles O'Brien, and an anonymous coleopterist reviewed this manuscript.

\section{Literature Cited}

Anderson, D. M. 1962. The weevil genus Smicronyx in America north of Mexico. Proceedings of the United States National Museum 113:185-372.

Korotyaev, B. A., A. S. Konstantinov, and C. W. O'Brien. 2000. A new genus of the Orobitidinae and discussion of its relationships (Coleoptera: Curculionidae). Proceedings of the Entomological Society of Washington 102(4):929-956.

O'Brien, C. W., and D. M. Anderson. 1996. A catalog of the Coleoptera of America north of Mexico. Family: Curculionidae; Subfamily Erirhininae. U.S. Department of Agriculture Handbook Number 529-143f: x + 40 pp.

Reidel, A., and C. W. O'Brien. 1995. A new species-group of Ottistira Pascoe from New Guinea (Coleoptera: Curculionidae: Entiminae: Ottistirini). Invertebrate Taxonomy 9:247-277.

(Received 20 December 2005; accepted 29 January 2006. Publication date 2 November 2006.) 